\title{
Role of Diacerein in osteoarthritis.
}

1. FCPS (Medicine)

Assistant Professor Medicine

King Edward Medical University.

2. FCPS (Medicine)

Assistant Professor Rheumatology

Mayo Hospital Lahore.

3. FCPS (General Surgery)

Consultant General Surgery

$\mathrm{CMH}$, Lahore.

4. FCPS (Pediatrics)

Assistant Professor Pediatrics STMU/SCM.

Correspondence Address:

Dr. Sahira Aaraj

Department of Pediatrics

STMU/SCM.

sahiraaaraj74@gmail.com

Article received on:

04/02/2021

Accepted for publication:

08/04/2021

\begin{abstract}
Samara Siddique', Yasir Imran², Asma Rizwan ${ }^{3}$, Sahira Aaraj $^{4}$
\end{abstract}
ABSTRACT... Objectives: To evaluate the role of Diacerein among patients with OA. Study Design: Retrospective Case Series. Setting: Mayo Hospital, Lahore. Period: April 2020 to September 2020. Material \& Methods: The study was conducted among forty patients with OA (grade II to IV according to ACR criteria) at Department of Rheumatology (EMW), Mayo Hospital, Lahore. Baseline WOMAC (Western Ontario and McMaster Universities Arthritis Index) and VAS (Visual Analogue Scale) was noted. Diacerine, 100mg in bd (twice a day) dose was given for 6 months. After 6 months, WOMAC and VAS were noted and \%age improvement was calculated. Results: The mean WOMAC at presentation was 48.78+6.42 and after treatment was $36.20+20(p<0.05)$. The mean VAS before and after treatment was $5.88+1.20$ and $3.58+3.22$, respectively $(p<0.05)$. A $20 \%$ improvement was seen among $40 \%$ patients. The efficacy of the drug was labeled as yes in $40 \%$ patients. One (2.5\%) patients suffered from diarrhea, and one (2.5\%) patient had raised LFTs after treatment. Conclusion: Diacerine significantly improves the mean WOMAC and VAS score after 6 months of therapy. The efficacy is also high. So, it can be considered as an alternative drug among symptomatic patients with $\mathrm{OA}$ in whom the symptoms do not improve after conventional analgesics.

Key words: $\quad$ Diacerein, Efficacy, Improvement, Osteoarthritis, VS, WOMAC.

Article Citation: Siddique S, Imran Y, Rizwan A, Aaraj S. Role of Diacerein in osteoarthritis. Professional Med J 2021; 28(11):1552-1556.

https://doi.org/10.29309/TPMJ/2021.28.11.6400

\section{INTRODUCTION}

Osteoarthritis is a gradually progressing joint disease which involves softening of cartilage followed by its loss, sclerosis of subchondral bone with cyst and osteophyte formation. ${ }^{1}$ The presenting features are joint pain, effusion, rigidity and lack of functional mobility. Incidence of knee osteoarthritis in the West is 18 to $25 \%$ in males and 24 to $40 \%$ in females older than 60 years. $^{2}$ A study in Pakistan has shown that $28 \%$ of the urban and $25 \%$ of the rural population were having knee osteoarthritis. ${ }^{3}$ Although all the three compartments of knee may be affected, medial compartment involvement is more common. This is due to repetitive forces generated during walking which cause varus movement at knee creating a large compressive force in the medial compartment. ${ }^{4}$

The main objectives in management of osteoarthritis are to reduce the symptoms, functional disability and limit the progression of structural changes. Analgesics and nonsteroidal anti-inflammatory drugs are main stay of treatment. $^{7}$

Research over the last two decades has shown that the cytokine interlukin-1-beta (IL-1B) plays a key role not only cartilage degradation but also in subchondral bone remodelling, chondrocyte apoptosis and joint inflammation. ${ }^{8}$ The production of nitric oxide (NO) which is stimulated by pro inflammatory cytokines, is involved in cartilage catabolism and also may induce apoptosis of chondrocytes. Many drugs like glucosamine sulphate, Nimesulide were studied in the past but Diacerein, an anthraquinone derivative, is an (IL1B) inhibitor and is considered as a symptomatic slow acting drug in OA (SYSADOA)..$^{9}$ This drug has a slow onset of efficacy and long carry-over effect once treatment is interrupted. ${ }^{10,11}$ It slows down the breakdown of cartilage and relieves 
pain and swelling. Its side effects are diarrhoea, heartburn, soft stools, stomach pain and frequent bowel movements. ${ }^{12}$

Osteoarthritis is a disorder with significant disability and so far, no gold standard treatment options are available. The physicians have to rely upon the disease modifying or structure modifying agents. Diacerein, has been tested as a structure modifying agent in some studies. However, the data is insufficient to label its usefulness in terms of efficacy. This study was conducted to see the usefulness of the drug in reducing the pain and inflammation in this disease.

\section{MATERIALS \& METHODS}

This was a retrospective case series which was conducted among 40 patients (including both male and female) with the age $>50$ years. The study was conducted at Mayo Hospital, Lahore. We included all the patients with painful primary knee osteoarthritis of grade II, III or IV diagnosed according to ACR criteria. ${ }^{13}$ Patients with no change in dose of Non Steroidal Anti Inflammatory Drugs for last four weeks were included. The patients with secondary osteoarthritis (like metabolic or inflammatory), on heavy use of steroids (for more than 1 year), who have taken intra articular injections in the last three months and with history of trauma of knee joint for less than six months were excluded from the study. Signed informed consent was obtained from the patient and confidentiality was maintained. Routine investigations were done and co morbidities were noted. Severity of disease was assessed by WOMAC score ${ }^{14}$ that include grades of pain, stiffness and effect on physical activity through a questionnaire. The pain was also measured by a subjective pain scale i.e. Visual Analogue Score (VAS),${ }^{15}$ which was scored from 0 to 10 by the patient himself. Both WOMAC and VAS were noted at the time of presentation for all patients taken as base line WOMAC an VAS. All the patients were given Oral Diacerin (100mg in two divided dose over a period of six months. After 6 months, the patients were evaluated with WOMAC score and VAS. Efficacy of Diacerin was labeled as yes if there i.e. $>20 \%$ improvement in WOMAC score or VAS. All this information will be collected through an especially formulated proforma which is provided herewith. Statistics were analyzed through SPSS version 20.

\section{RESULTS}

The study was carried out among 40 patients. The patient's age was $58.00+7.07$ years (range was 50 - 83 years). Thirty one (77.5\%) patients were in age group of $50-60$ years. There were $10(25 \%)$ male patients, while 30 (75\%) patients were female. The mean BMl of the patients was $28.93+5.02 \mathrm{~kg} / \mathrm{m}^{2}$. Among the co-morbid conditions, there were $4(10 \%)$ patients who suffered from diabetes mellitus and 19 (47.5\%) suffered from diabetes mellitus. Twenty seven (42.5\%) patients had no associated co-morbid conditions. There were $12(30 \%)$ patients had grade II OA, 11 (27.5\%) had grade III OA and $17(42.5 \%)$ had grade IV OA. The difference in the mean WOMAC score and VAS at base line and at 6 months follow up was found statistically significant $(p<0.05)$. (Table-I) More than 20\% improvement in WOMAC score and VAS was seen among 16 (40\%) patients while rest of 24 (60\%) patients did not show any improvement $>20 \%$. The distribution of \%age improvement is discussed in the Table-II.

The range of $\%$ age improvement was $10-20 \%$ in $24(60 \%)$ patients, $21-30 \%$ in $9(22.5 \%)$ patients, $31-40 \%$ in 5 (12.5\%) patients, 41 $50 \%$ in 1 (2.5\%) patients, $51-60 \%$ in 1 (2.5\%) patients. None of the patients showed $\%$ age improvement above $60 \%$. The stratification of the $\%$ age improvement according to grades of OA showed maximum improvement in patients with grade II OA. (Table-II) The efficacy of the drug is described in Figure-1.

\begin{tabular}{|c|c|c|}
\hline & $\begin{array}{l}\text { WOMAC Score } \\
\text { (Mean + SD) }\end{array}$ & VAS (Mean + SD) \\
\hline Base line & $48.78+6.42$ & $5.88+1.20$ \\
\hline At follow up & $36.20+20.22$ & $3.58+3.22$ \\
\hline$p$-value* & $0.001 * *$ & $0.001 * *$ \\
\hline \multicolumn{3}{|c|}{$\begin{array}{l}\text { Table-I. Distribution of patients by mean WOMAC } \\
\text { score and VAS at base line and improvement in } \\
\text { WOMAC score and VAS at } 6 \text { months follow up. } \\
\text { * Student's t-test } \quad * * \text { Statistically significant }\end{array}$} \\
\hline
\end{tabular}




\begin{tabular}{|l|c|c|}
\hline \multirow{2}{*}{ Grades of OA } & \multicolumn{2}{|c|}{$\%$ age Improvement } \\
\hline Grade II $(n=12)$ & 9 & $\%$ \\
\hline Grade III $(n=11)$ & 5 & $75 \%$ \\
\hline Grade IV $(n=17)$ & 2 & $45.5 \%$ \\
\hline
\end{tabular}

Table-II. The stratification of the \%age improvement DISCUSSION according to grades of $O A$.

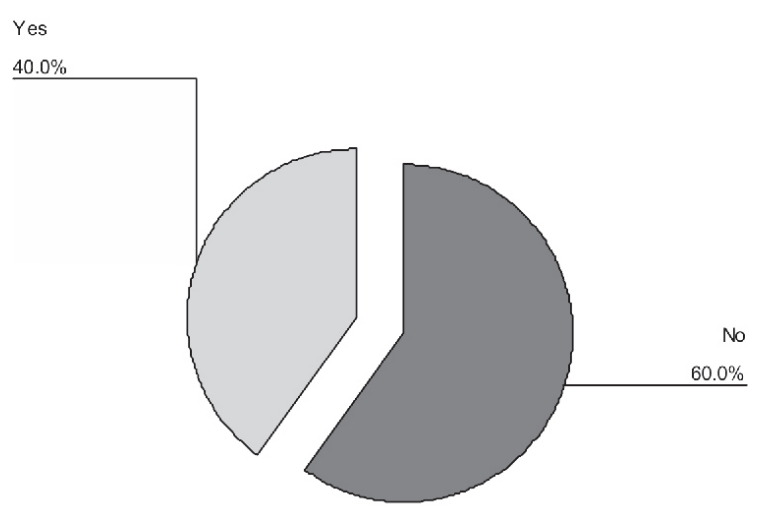

Figure-1. Distribution of patients by efficacy.

Recently, the use of Diacerein, as a structure modifying agent for treatment of $\mathrm{OA}$ is under practice. However, a little is known about its efficacy and improvement in functional outcome. This study was conducted to expand our knowledge about the efficacy and improvement in pain in OA patients over a period of 6 months among 40 patients. The results were in favor of Diacerein with statistically significant improvement in mean WOMAC score and VAS before and after treatment. The efficacy of Diacerein in terms of improvement in pain $>20 \%$ was also quite attractive.

Diacerein is a low slow acting inhibitor of production of $\mathrm{IL}-1 \mathrm{~B}$ and its role as disease modifying agent in vitro has also been suggested in literatures. ${ }^{16}$ Previously, Dougados $M$, et $\mathrm{al}^{17}$, conducted a prospective cohort study involving 521 patients with OA. Diacerein was found to be useful in causing structural modification in hip OA. The main outcome parameters were radiographic measurement of joint space. ${ }^{17}$ In another study by Louthrenoo, et al $^{18}$ it was noted that, diacerein was successful in providing pain relief and improving functional ability in patients with clinical symptoms of knee OA. Fagnani, et $\mathrm{al}^{19}$ carried out a ranodomized clinical trial with atleast 100 individuals with $\mathrm{OA}$ in each of the treatment groups (diacerein plus conventional treatment and conventional treatment alone). They concluded that $60 \%$ of the patient's receiving diacerein plus conventional therapy evaluated the net results as outstanding, as compared to $26 \%$ of patients who received conventional treatment. In a systemic metanalysis, by Rintelen, et $\mathrm{al}^{20}$, a statistically significant improvement in pain and function was found among patients with $O A$. Moreover, diacerein was also found to have an extended analgesic effect providing extra pain relief as compared to placebo or NSAID for many weeks after stopping the therapy. ${ }^{21}$

We studied 40 patients in which the functional improvement and improvement in pain was observed. We applied WOMAC scale which is based on questionnaire and is easy and simple to apply. Moreover, we also applied VAS which is also very simple. Both the scales were selected in order to assess both function and pain control. Different other pain scales like OMERACT- $6^{22}$, the Lequesne Functional Severity Index ${ }^{23}$ has also been used in literature. However, both WOMAC and VAS are simple, reliable and easy to use. In a random placebo controlled study lasting for 16 weeks enrolling 484 patients with knee $\mathrm{OA}$, Pelletier ${ }^{24}$ and his collegues concluded that diacerein $50 \mathrm{mg}$ given two times a day improved both VAS and WOMAC scores quite remarkably.

In our study, we also observed that most of the improvement in WOMAC score was less than $20 \%$ and none of the patients showed improvement more than $60 \%$. Another observation was that almost $75 \%$ patients with grade II OA showed improvement, while only $11.8 \%$ patients in grade III OA showed improvement. So, this shows that \%age improvement may also be related to the severity of OA.

In our study, only two patients got complications, which were dose limiting. Diarrhea was observed in $2.5 \%$ patients, while deranged LFTs in other $2.5 \%$ patients. Diarrhea was also noted by 
Dougados M, et al. ${ }^{17}$ They observed that this was the most common side effect. It occurred in $46 \%$ in the diacerein group as compared to $12 \%$ in the placebo group; P-value 0.001). However, the diarrhea was not dose limiting in their study and approximately $76 \%$ patients in their study had mild diarrhea. Discoloration of urine may also be a side effect, but it was dose limiting in our study.

This study had certain limitations. This was a single center study with a limited population size. Most of the population represented the poor community. The sample size was limited. So, there is need for other multicenter clinical trials to be carried on to determine the actual benefits of the drug.

\section{CONCLUSION}

Diacerein, has significantly provided the analgesic effect and improved functional ability of the patients with OA of knee joint. Moreover, this is also found to be safe and effective. So, its use is suggested among patient with resistant to conventional analgesic drugs.

Copyright(C) 08 Apr, 2021.

\section{REFERENCES}

1. CharlesWorth J, Fitzpatrick J, Orchard Zhang W, Doherty M, Peat G, Zeinstra B, Kirschner S, Leeb BF et al. EULAR evidence-based recommendations. Ann Rheum Dis. 2010; 69 (3):483-9.

2. Soininen JV, Paavolainen PO, Gronblad MA, Kaapa EH. Validation study of a Finnish version of the Western Ontario and McMasters University osteoarthritis index. Hip International. 2008; 18: 108-11.

3. Franson M, Bridgett L, March L, Hoy D, Penserga E, Brooks P. Epidemiology of osteoarthritis in Asia. Inter $\mathrm{J}$ of Rheum Dis 2011; 14: 113-21.

4. Iqbal MN, Haidri FR, Motiani B, Mannan A. Frequency of factors associated with osteoarthritis. J Pak Med Assoc. 2011; 61(8): 786-9.

5. Englund M, Felson DT, Guermazi A, Roemer FW, Wang $\mathrm{K}$, Crema MD et al. Risk factors for medial meniscal pathology on knee MRI in older US adults: A multicentre prospective cohort study. Ann Rheum Dis. 2011; 70:1733-9.
6. Levinger P, Menz HB, Fotoohabadi MR, Feller JA, Bartlett $J R$, Bergman NR. Foot posture in people with medial compartment knee osteoarthritis. Journal of Foot and Ankle Research 2010; 3: 29.

7. Kennedy S, Moran M. Pharmacological treatment of hip and knee. BCMJ. 2010; 52: 404-9.

8. Neilson RH, Stoop R, Leeming DJ, Qvist P, Christiansen $\mathrm{C}$ and Karsdal MA. Evaluation of cartilage damage by measuring degradation products in joint. Biomarkers. 2008; 13: 79-87.

9. Kafil N, Hadi MI, Waseem B. Comparison between glucosamine sulphate and Nimesulide therapies in osteoarthritis. Journ Surg Pakistan Intern. 2010; 15: (2).

10. Boileau C, Tat SK, Pelletier JP, Cheng S, Pelletier JM. Diacerein inhibits the synthesis of resorptive enzymes and reduces osteoclastic differentiation/ survival in osteoarthritic subchondral bone: A possible mechanism for a protective effect against subchondral bone remodelling. Arthritis Research \& Therapy 2008; 10: 71.

11. Rintelen B, Neumann K, Berkhurad F. A meta-analysis of controlled clinical studies with diacerin in the treatment of OA. Arch Intern Med. 2006; 166: 1899906.

12. Renapurkar DK, Mathur S, RAO KLJ. Evaluation of efficacy and safety of Diacein in osteoarthritis of knee joint. Intern Journ Pharma, Bio Sciences 2010, Vol. 1: I-11.

13. Altman R, Asch E, Bloch D, Bole G, Borenstein D, Brandt $\mathrm{K}$, et al. Development of criteria for the classification and reporting of osteoarthritis: Classification of osteoarthritis of the knee. Arthritis Rheum 1986; 29:1039-49.

14. Bellamy N, Buchanan WW, Goldsmith $\mathrm{CH}$, Campbell J, Stitt LW. Validation study of WOMAC: A health status instrument for measuring clinically important patient relevant outcomes to antirheumatic drug therapy in patients with osteoarthritis of the hip or knee. Journal of Rheumatology 1988; 15:1833-40.

15. Carlsson AM. Assessment of chronic pain. I. Aspects of the reliability and validity of the visual analogue scale. Pain 1983; 16:87-101.

16. Mendes AF, Caramona MM, de Carvalho AP, Lopes $M C$. Diacerhein and rhein prevent interleukin-1Binduced nuclear factor-kB activation by inhibiting the degradation of inhibitor kB-a. Pharmacol Toxicol 2002; 91:22-8. 
17. Dougados M, Nguyen M, Berdah L, Mazieres B, Vignon $E$, Lequesne $M$. Evaluation of the structure-modifying effects of diacerein in hip osteoarthritis: ECHODIAH, a three-year, placebo-controlled trial. Evaluation of the Chondromodulating Effect of Diacerein in OA of the Hip. Arthritis Rheum 2001; 44:2539-47.

18. Louthrenoo W, Nilganuwong S, Aksaranugraha S, Asavatanabodee P, Saengnipanthkul S, Thai G. The efficacy, safety and carry-over effect of diacerein in the treatment of painful knee osteoarthritis: A randomized, double-blind, NSAID-controlled study. Osteoarthritis Cartilage 2007; 15:605-14.

19. Fagnani F, Bouvenot G, Valat JP, et al. Medicoeconomic analysis of diacerein with or without standard therapy in the treatment of osteoarthritis. Pharmacoeconomics 1998; 13:135-46.

20. Rintelen B, Neumann K, Leeb BF. A meta-analysis of controlled clinical studies with diacerein in the treatment of osteoarthritis. Arch Intern Med 2006; 166:1899-906.
21. Lequesne M, Berdah L, Gérentes I. Efficacy and Safety of Diacerein for the treatment of Knee and Hip Osteoarthritis [Efficacité et tolérance de la diacerhéine dans le traitment de la gonarthrose et de la coxarthrose]. La Revue du Praticien 1998; 48:S31S35.

22. Pham T, Henanff AL, Ravaud P, Dieppe $P$, et al. Evaluation of symptomatic and structural efficacy of a new hyaluronic acid (HA) compound, (NRD101), when compared to diacerein and placebo in oneyear randomized controlled study in symptomatic knee osteoarthritis. Annals of Rheumatic Diseases 2004; 63(12):161-7.

23. Pelletier JP, Yaron M, Haraoui B, et al. Efficacy and safety of diacerein in osteoarthritis of the knee: $A$ double-blind, placebo-controlled trial. The Diacerein Study Group. Arthritis Rheum 2000; 43:2339-48.

\begin{tabular}{|c||c|c|c|}
\hline \multicolumn{2}{|c|}{ AUTHORSHIP AND CONTRIBUTION DECLARATION } \\
\hline No. & \multicolumn{1}{|c|}{ Author(s) Full Name } & \multicolumn{1}{|c|}{ Contribution to the paper } & Author(s) Signature \\
\hline 1 & Samara Siddique & $\begin{array}{l}\text { Oritinal data, Final drafting of } \\
\text { manusctipt. }\end{array}$ & \\
\hline 2 & Yasir Imran & $\begin{array}{l}\text { Data collection and } \\
\text { manuscript writing. } \\
\text { Data collection and } \\
\text { manuscript writing. } \\
\text { Statistical analysis, Results } \\
\text { writing. }\end{array}$ & \\
\hline 4 & Sahira Aaraj & Asma Rizwan & \\
\hline
\end{tabular}

